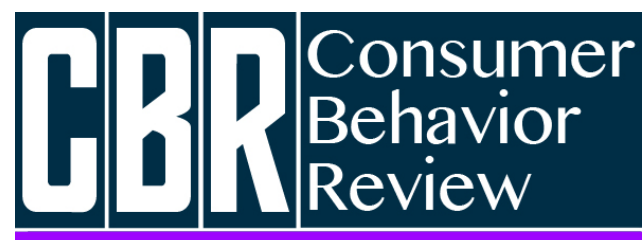

Revista Comportamento do Consumidor
Rezende, S. R. G., \& Coelho, C. (2021). Influência dos Reforços Utilitários e Informativos na Avaliação do Consumidor em Testes às Cegas e Marcas Reveladas. Consumer Behavior Review, 5(1), 60-76.
ISSN: 2526-7884

Editor: Prof. Dr. Marconi Freitas da Costa

E-mail: cbr@ufpe.br
Avaliação: Double blind review

Recebido: 18 de Junho, 2020

Aceito: 8 de dezembro, 2020

\title{
INFLUÊNCIA DOS REFORÇOS UTILITÁRIOS E INFORMATIVOS NA AVALIAÇÃO DO CONSUMIDOR EM TESTES ÀS CEGAS E MARCAS REVELADAS
}

\author{
Influence of utility and informational reinforcements on consumer assessment in blind and \\ revealed brand tests
}

\author{
Sônia Regina Gouvêa Rezende ${ }^{1}$ \\ ORCID: http://orcid.org/0000-0003-4722-3749 \\ E-mail: profsoniarez@gmail.com \\ Cristiano Coelho ${ }^{2}$ \\ ORCID: http://orcid.org/0000-0002-8211-4962 \\ E-mail: cristicoelho@gmail.com
}

${ }^{1}$ Universidade Estadual de Goiás, Anápolis, Brasil

${ }^{2}$ Pontifícia Universidade Católica de Goiás, Goiânia, Brasil

\begin{abstract}
Resumo
As marcas saíram do âmbito de produto para cultura de consumo, formada pela percepção dos consumidores a partir das experiências com o produto e a organização. A concorrência aumentou e as empresas adotam estratégias para se diferenciar ao trabalhar com marcas próprias. Para analisar o comportamento dos consumidores, aplicou-se o modelo teórico Behavioral Perspective Model (BPM) com objetivo de mensurar os níveis de reforços utilitários de cookies no teste às cegas e os níveis de reforços utilitários e informativos, no
\end{abstract}

\begin{abstract}
Brands departed from the scope of products to a consumer culture, created upon the consumers perception from experiences with the product and the organization. Competition has increased and companies adopt strategies to differentiate themselves when working with own brands. To analyze consumer behavior, the theoretical model Behavioral Perspective Model (BPM) was applied to measure the cookies levels of utility reinforcement, in the blind test, and levels of utility and informational reinforcements, in
\end{abstract}


teste de marcas reveladas. No teste de marcas reveladas, a marca de fabricante com maior nível de reforço informativo apresentou maior preferência e evidenciou-se uma baixa discriminabilidade entre as marcas próprias. 0 teste às cegas não apresentou diferenças significativas entre a marca de fabricante e marcas próprias, indicando que as marcas possuem reforços utilitários semelhantes, podendo ser substituídas entre si em termos funcionais.

Palavras-chaves: comportamento de consumidor; reforços informativos e utilitários; teste às cegas e de marcas reveladas; marcas de fabricantes; marcas próprias. the test of revealed brands. In the test of revealed brands, the manufacturer brand with the highest level of informative reinforcement showed greater preference and showed low discrimination between the own brands. The blind test did not show significant differences between the manufacturer's brand and own brands, indicating that the brands have similar utility reinforcements and can be replaced in functional terms.

Keywords: consumer behavior; informative and utilitarian reinforcements; blind and revealed test marks; manufacturers' brands; own marks.

\section{INTRODUÇÃO}

A utilização de marcas como forma de identificação de um produto é uma prática comumente utilizada há séculos. Desde os períodos mais remotos da civilização, o homem tenta copiar e criar formas que facilitem a sua comunicação e as relações com os outros (Rezende, 2013). Após a Revolução Industrial, em meados de 1883, determinados fabricantes passaram a proteger seus produtos "marcando-os", para garantir a qualidade e a segurança dos itens comercializados (Aaker, 1998; Keller \& Machado, 2006; Oliveira, 2005). A partir desse período, surgiram as grandes empresas e o consequente aumento de oferta de produtos influenciou que as marcas tornassem mundialmente conhecidas, levando a uma relação de afastamento entre o fabricante e o consumidor (Souza \& Nemer, 1993).

O Comitê de Definições da American Marketing Association (1960) descreve que a marca é caracterizada pelo nome, termo, símbolo, desenho ou uma combinação desses elementos para identificar os bens ou serviços de um fornecedor e diferenciá-lo da concorrência. Porém, Kotler (2000) assegura que em recentes teorias a marca tornou-se muito mais do que isso. De acordo com ele, a marca ultrapassa o conceito de produto em si mesmo, envolvendo toda a empresa, as suas estratégias e os seus objetivos, e ainda, aproxima o consumidor, materializando os seus próprios desejos e necessidades. É neste sentido que De Chernatony e Dall'Olmo Riley (1998) afirmam que a marca extrapola as dimensões racionais e tangíveis, relacionadas ao desempenho e ao que a diferencia de alguma forma de outros produtos destinados a satisfazerem uma mesma necessidade, podendo assim, alcançar as dimensões mais simbólicas, emocionais e intangíveis, relacionadas com o que ela representa.

Como resultado do desenvolvimento tecnológico, a produção tornou-se homogênea, apresentando produtos com características de produção em escala (Amrouche \& Yan, 2012). Desse modo, as marcas de fabricantes líderes de mercado, frequentemente procuradas pelos consumidores, têm maior poder de negociação juntos aos varejistas e atacadistas, e são pontos de referência na guerra de preços entre esses canais. Para competir com as marcas líderes de mercado em seu segmento as empresas optaram por produzir marcas próprias como um meio de diferenciar-se dos concorrentes, de crescer por meio da extensão da marca própria e reforçar as suas relações com os consumidores (Miquel-Romero, Caplliure-Giner, \& Adame-Sánchez, 2014; Oliveira, 2005). Marca própria se caracteriza por aqueles produtos vendidos sob a marca do varejista, que pode ter o nome da própria cadeia varejista ou um nome de uma marca de uso exclusivo para as suas lojas, mas que normalmente não possuem unidades produtoras (Private Label Manufacturers Association, 2017). 
Embora a maioria das empresas não possa controlar as variáveis ambientais, elas podem gerenciar suas atividades para fornecer valor superior por meio da diferenciação de suas marcas (Aaker, 2001). Neste contexto, pesquisas científicas têm abordado de diferentes formas o comportamento do consumidor. De forma geral, este indivíduo é visto como participante de uma condição de decisão, na busca de resultado da sua procura por informação e ações do marketing (Urban, Hulland, \& Weinberg, 1993).

O processo de escolha é complexo, já que há um número superior de fatores que vão além das relações diretas como os eventos físicos, porque o ambiente social exerce um controle sobre o comportamento (Skinner, 1978). Rajala e Hantula (2000) complementam que os consumidores procuram, adquirem e consomem e bens e serviços, o que é um elemento fundamental do comportamento, uma atividade biológica básica e não simplesmente um epifenômeno da prática mercadológica.

Então se percebe que é relevante entender melhor o comportamento dos consumidores atuais e os em potenciais. Desse modo, optou-se por estudar o comportamento do consumidor na comparação entre testes cegos e testes com marcas reveladas a partir do Behavioral Perspective Model (BPM - Modelo na Perspectiva Comportamental) de Foxall $(1990,1992,1998)$ que tem como abordagem prioritariamente o Behaviorismo Radical de Skinner $(1953,1957,1974)$. O BPM fornece uma alternativa teórica consistente para interpretação, análise do comportamento do consumidor e comparação dos efeitos dos reforços informativos das marcas de fabricantes e marcas próprias nos testes às cegas, enquanto nos testes de marcas reveladas foram analisados e comparados os efeitos informativos e utilitários, também das referidas marcas, destacando o papel das variáveis situacionais e contextuais. Apesar de sua efetividade na compreensão do comportamento do consumidor demonstrada em pesquisas experimentais nos últimos anos (Foxall, 2005; Foxall, Oliveira-Castro, James \& Schrezenmaier, 2006; Nalini, Mello Cardoso, \& Cunha, 2013), não foram encontrados trabalhos de investigação baseados em testes cegos.

0 insight deste estudo teve como fontes as pesquisas de Pohjanheimo e Sandell (2009) e Vraneševicv e Stančec (2003) que foram realizadas para examinar a natureza dos efeitos de reconhecimento da marca na compra de diferentes produtos domésticos comuns em marcas de fabricantes, já De Wulf, Odekerken-Schröder, Goedertier e Van Ossel (2005), Ejye Omar (1994) compararam marca de fabricante e marca própria. Os resultados relevaram que a lealdade à marca leva a certas vantagens de marketing, como redução de custos de marketing, geração de novos clientes, maior alavancagem comercial, aumento de participação de mercado e preço relativo, redução da motivação de busca, boca-a-boca favorável e maior resistência dos clientes leais ao mercado competitivo.

\section{PATROCÍNIO DAS MARCAS}

A tomada de decisão do consumidor tem sido de interesse contínuo para os investigadores da temática de consumo. Mais especificamente, a escolha da marca é um dos vários processos nos quais os indivíduos ou grupos se engajam ao consumir produtos (Silva, 2007). Desde a década de 1960, a expansão do estudo de marketing em pesquisas de consumo contribuiu para ampliação das pesquisas de consumo, especialmente do comportamento do consumidor por meio do impacto da marca (Foxall, Oliveira-Castro, James \& Schrezenmaier, 2006).

Aaker (1998) comenta que, por longa data a marca exerceu um papel restrito à identificação do produto. Porém Aaker (2007) e De Chernatony (2005) observam que as marcas podem ser interpretadas em várias dimensões, como, por exemplo: logomarca, instrumento legal de propriedade, uma segurança (fator de redutor de risco para o consumidor), um posicionamento, uma personalidade, um conjunto de agregação de valores, uma identidade e imagem ou um canal de relacionamento da empresa com o cliente. Nesse sentido, a marca ultrapassa seu papel restrito ao produto. Desse modo, observa-se que a construção de uma marca e sua gestão envolve tanto aspectos legais de identificação visual e/ou meio de diferenciação, como o conceito holístico da marca, incluindo dimensões funcionais, emocionais, relacionais e estratégicas (De Chernatony \& Dall'Olmo Riley, 1998). 
A escolha da posição da marca deve ter como base uma decisão econômica envolvendo resposta de mercado (Kumar \& Steenkamp, 2008). Os varejistas e atacadistas estão conscientes de que uma marca forte é uma fonte de vantagem competitiva para qualquer empresa. Com efeito, para que um posicionamento seja efetivo, faz-se necessário uma análise evidenciando as estratégias das decisões de patrocínio da marca: marca do fabricante, marca própria, dentre outras.

Kumar e Steenkamp (2008), Olson (2012), Serralvo, Prado e Leal (2007) e Tarziján (2007) definem marcas de fabricante como sendo aquelas de propriedade ou controladas por uma organização comprometida com o processo de produção e que tem a responsabilidade de estabelecimento de identidade da marca e distribuição. Piato (2011) ressalta que as marcas de fabricantes líderes de mercado não geram fidelidade ao canal de distribuição, já que estão disponíveis em diversas redes varejistas e, para atrair a atenção do consumidor, estão sempre com descontos significativos. Outro aspecto relevante, relatado por Piato (2011) em relação a essas marcas de fabricante, é sua preferência por parte dos consumidores, que por não dispor de muito tempo, oportunidade ou capacidade para analisar as alternativas no ponto de venda, consolidam a compra pela garantia de qualidade pré-estabelecida, simplificando o processo de seleção. Ademais, as mercadorias com marca de fabricante geralmente oferecerem produtos com maior fatia de mercado (market share) pelo histórico de propagandas (Chen, Narasimhan, John, \& Dhar, 2010; Kumar \& Steenkamp, 2008).

Sobre o outro escopo do patrocínio, nos últimos anos as marcas próprias tornaram-se muito importante para os comerciantes como um meio de diferenciar-se dos concorrentes, de crescer por meio da extensão da marca própria e reforçar as suas relações com os consumidores (Miquel-Romero, Caplliure-Giner \& Adame-Sánchez, 2014; Oliveira, 2005). Chen et al.(2010) definem marca própria como uma marca de propriedade ou controlada por uma empresa e vendida, exclusivamente, em uma única cadeia de varejo ou grupo. Historicamente, quando introduzidos no mercado, os produtos de baixa qualidade das marcas próprias não concorriam com os produtos de marcas dos fabricantes (Amrouche \& Yan, 2012; Paula, 2008). Porém, com o aumento da competitividade entre os varejistas, as marcas próprias passaram a funcionar com uma nova estratégia.

As crescentes vendas das marcas próprias representam desafios significativos para as marcas de fabricante em todo o mundo. No Brasil, as marcas próprias seguem se consolidando na economia nacional (Nielsen, 2017). Yokoyama (2010) argumenta que o desenvolvimento de marcas próprias é um bom investimento gerador de lucros porque proporcionam altas margens brutas e melhor rentabilidade; cria e ajuda a manter a imagem corporativa da marca; consagra a reputação e auxilia a manter a lealdade à marca da empresa; alcança economia de escala (conceito econômico cujo significado é a possibilidade de reduzir o custo médio de um determinado produto pela diluição dos custos fixos em um número maior de unidades produzidas) e minimização de custos, visto que investimentos na construção da imagem por meio de propaganda são menores; e, ainda, permite aos lojistas aumentarem o poder de negociação com os fabricantes de seus produtos.

\section{EFEITOS DAS MARCAS EM TESTES DE MARCAS REVELADAS E TESTES ÀS CEGAS}

Na avaliação do comportamento do consumidor, Hoyer e Brown (1990) concluíram que a consciência da marca exerce influência na escolha e na prova e experimentação dessa marca. Para os autores, a consciência da marca representa o conhecimento da marca, envolvendo pelo menos, o reconhecimento do nome da marca e que varia desde o simples reconhecimento da marca até uma estrutura cognitiva, resultante do histórico de experiências desenvolvida com base em informações detalhadas. Hoyer e Brown (1990) sugeriam outros possíveis efeitos do conhecimento da marca que mereciam investigação, como a provável exposição prévia à informação da marca por meio de publicidade ou outras fontes que resultassem na formação de um esquema relacionado às expectativas do consumidor em relação à marca.

Nesta perspectiva, Vraneševicv e Stančec (2003) pesquisaram vendas de patês e analisaram a percepção da marca pelo consumidor e o quanto ela afeta a avaliação das características funcionais do produto, principalmente a qualidade do produto. Quando os participantes saborearam os produtos por meio do teste de marca (nome da marca visível), a marca mais conhecida na indústria de carnes 
recebeu um percentual de $66,7 \%$ de preferência comparada a marca de patê ficou colocada em sexto lugar, na pesquisa de preferência previamente aplicada. Mas no teste às cegas, apenas $40 \%$ dos respondentes evidenciaram a marca de patê mais conhecida na indústria como a melhor. As principais conclusões de Vraneševicv e Stančec (2003) são que os consumidores não valorizam produtos baseados exclusivamente em suas características físicas e que, no processo de tomada de decisão de compra, ao escolher uma alternativa, os consumidores percebem primeiramente a marca como "um sinal de qualidade" e somente posteriormente valoram outros critérios em sua avaliação (aparência física e embalagem, preço, reputação da rede de varejo).

Pohjanheimo e Sandell (2009) avaliaram a exposição de uma marca e a atuação sobre o conhecimento que o consumidor tem desta marca, e notaram ser um determinante da escolha do consumidor. Os graus de gostos para sabores de iogurte foram avaliados por Pohjanheimo e Sandell (2009) em um teste de consumo com 162 participantes de um painel sob duas condições: cego e com informações completas sobre os produtos disponíveis. Os autores comentaram que as informações do produto com o nome do fabricante, marca, sabor e imagem do pacote comercial tiveram efeitos positivos e significativo nas pontuações de preferência de gosto pelos iogurtes.

Em testes comparativos de marcas, Ejye Omar (1994) selecionou três tipos de refrigerantes e os participantes da pesquisa foram convidados a avaliar os produtos de uma marca de fabricante e de seis marcas próprias de cada tipo de refrigerante: gosto às cegas (produtos não identificados); sabor revelado (produtos identificados); e sabor e embalagem revelados. Todos os pesquisados participaram das três maneiras de testes. Os respondentes classificaram cada produto em vários fatores, como efervescente, picante, doce, gratificante e refrescante. Os entrevistados também foram convidados a dizer o quanto eles pagariam por cada produto usando uma escala definida a partir da faixa de preço real no mercado.

Os resultados do experimento de Ejye Omar (1994) mostram como as marcas próprias foram posicionadas psicologicamente abaixo das marcas de fabricante em muitos níveis de escalas, mas foram relatadas como sendo particularmente de bom preço. A marca própria foi identificada e/ou vista como inferior à da marca de fabricante. No entanto, a conclusão básica ao teste às cegas não indicou diferenças significativas entre as marcas de fabricante e marcas próprias. Além do preço e do diferencial da embalagem, as marcas poderiam ser facilmente substituídas pela outra. Quase sessenta e sete por cento dos consumidores pesquisados por Ejye Omar (1994), preferiram a marca própria no teste às cegas, mas mudaram de opinião quando realizam a avaliação para sabor quando revelados os nomes das marcas expostos. 0 autor afirmou que, quando o elemento preço foi introduzido, as escolhas das marcas tornaram-se mais próximas, e concluiu que a mudança de opinião no teste quando se revelou os nomes das marcas foi devido mais à imagem da marca, que do gosto ou sabor. Desse modo, apenas alguns dos consumidores testados por Ejye Omar (1994) distinguiram marcas de fabricante e marcas próprias em altos níveis de escalas e com percentuais significativos nas diferenças de prova e experimentação sobre os dois tipos de marcas. Os resultados confirmam a crença comum de que os produtos de marca própria podem oferecer a mesma qualidade ou mesmo melhor que as marcas de fabricante, mas a um preço mais baixo.

$\mathrm{Na}$ mesma linha das preocupações levantadas acima, De Wulf et al. (2005) realizaram um estudo triplo de degustação de suco de laranjas para avaliar se as quatro marcas próprias estavam posicionadas de forma diferente quando comparadas a uma marca de fabricante em termos de valor da marca (brand equity), além de investigar se o brand equity das marcas próprias versus das marcas de fabricantes estavam determinados pela fidelidade das marcas, e finalmente se o patrocínio da loja tem uma influência no valor percebido das marcas próprias versus as marcas de fabricantes.

Com os resultados, De Wulf et al. (2005) identificaram que os consumidores, no teste de marca, expressaram uma preferência significativamente maior pelo suco da marca de fabricante do que no teste as cegas do mesmo suco. Este efeito principal implicou que a marca do fabricante possuía um forte referencial de marca, criando uma diferença percebida. Enquanto as marcas próprias não conseguiram criar pontuações significativamente diferentes nos testes de marca versus testes às cegas. Isso permitiu concluir que as marcas próprias não criaram diferença percebida positiva, perdendo significante brand equity (valor da marca). 
Os resultados de Labeaga, Lago e Martos (2007) corroboram com De Wulf e colaboradores (2005), mostrando que a lealdade comportamental da marca própria está na base do patrimônio da marca. Em suas pesquisas, Labeaga, Lago e Martos (2007) aplicaram o modelo logit (regressão com variável dependente binária - acontece/não acontece) de escolha de marca pelo consumidor para medir a fidelidade da marca própria e examinar se a fidelidade da marca própria é diferente em todas as categorias, e ainda observar a percepção de risco como uma variável explicativa de escolha. Na pesquisa, usou-se os dados do painel de varredura, fornecidos pela ACNielsen Espanha, nas compras domésticas de marcas de produtos de lavagem de roupas em duas categorias: sabão líquido para lavagem de roupa fina e sabão líquido para roupa não fina, durante um período de 2 anos, para mais de 1107 famílias.

Os resultados do estudo de Labeaga, Lago e Martos (2007) sugeriram que as marcas próprias recebiam lealdade comportamental porque a participação em testar uma marca é maior em categorias com baixo risco percebido pelo consumidor. Nesta pesquisa espanhola, os consumidores das marcas próprias apresentaram um comportamento padrão de escolha, uma vez que as famílias experimentam marcas próprias e tendo boas experiências, uma grande proporção desses consumidores continua comprando em ocasiões de compra subsequentes. Devido à boa qualidade e menor variabilidade de qualidade das marcas próprias na Espanha, o consumidor continua comprando as marcas próprias, e usa a lealdade para reduzir o risco de fazer um erro na compra de marcas de lojas. Em particular, no caso espanhol, as marcas próprias apresentam uma importante lealdade em termos globais, é maior do que a lealdade comportamental às marcas de fabricantes, uma vez que a marca é um dos motivos básicos da escolha de consumidor por um produto alimentício.

Neste contexto, a proposta para a análise do comportamento do consumidor (Foxall, 1990) denominada Behavioral Perspective Model (BPM) apresenta algumas adaptações e inovações conceituais e metodológicas com melhor escopo para abordar as demandas e características especificas dos fenômenos pertinentes que interferem no comportamento do consumidor, sob o ponto de vista da aplicação em marketing. Essa proposta se diferencia pela ênfase no papel das variáveis situacionais e contextuais como meio de sinalizar os benefícios utilitários e informativos decorrentes de um comportamento de consumo (Foxall, 1992).

\section{BEHAVIORAL PERSPECTIVE MODEL (BPM)}

Foxall (1987) e Oliveira-Castro e Foxall (2005) afirmam que o BPM apresenta em sua base teórica de análise do comportamento, os conceitos do Behaviorismo Radical de Skinner $(1953,1957$, 1974), utilizando a contingência tríplice como instrumento teórico. A Análise do Comportamento enfatiza o papel das variáveis situacionais e históricas na determinação do comportamento, com especial atenção para os eventos que antecedem e as que seguem as respostas dos indivíduos e defende a adoção de análises externas de comportamento, com pouco uso de construtos hipotéticos em suas teorias. Um dos conceitos centrais da teoria operante é a contingência de três termos ( $\mathrm{S}$ : $\mathrm{R} \rightarrow$ $\left.\mathrm{S}^{\mathrm{R}}\right)$, que sinaliza que respostas $(\mathrm{R})$ são reforçadas $\left(\mathrm{S}^{\mathrm{R}}\right)$ ou punidas, na presença de situações ou estímulos discriminativos ( $\mathrm{S}^{\mathrm{D}}$ ).

Na contingência de três termos, $S^{D}: R \rightarrow S^{R}$ (estímulo discriminativo, resposta e consequência), SD é uma situação presente ou antecedente que pode ser descrita em termos de estímulos chamados discriminativos pela função controladora que exerce sobre o comportamento ao sinalizarem a probabilidade de uma resposta ser reforçada em função dos seus reforços passados; $\mathrm{R}$ é algum comportamento do indivíduo, que se emitido na presença de tais estímulos discriminativos tem como consequência SR, alguma alteração no ambiente, que não ocorreria se tal comportamento fosse emitido na ausência dos referidos estímulos discriminativos (SD) ou se o comportamento (R) não ocorresse (Todorov, 2012).

De acordo com o BPM, o comportamento do consumidor ocorre na intersecção entre o histórico de aprendizado do consumidor e a configuração atual do comportamento, ou seja, na situação do consumidor, em que atributos de produto, da marca e de serviço, incluindo preço, podem ser interpretados como eventos programados de reforço (isto é, benefícios) e aversivos (Foxall; 1990; 1997; 2005; Nalini, Mello Cardoso, \& Cunha, 2013). Fabricantes, varejistas e gerentes de marca 
direcionam todos os seus esforços para modificar e modelar as propriedades reforçadoras e aversivas dos atributos de seus produtos e marcas, de modo a torná-los mais atraentes para o consumidor (Oliveira-Castro et al., 2008).

Em situações de prática de consumo o comportamento do consumidor resultará em consequências de eventos reforçadores e punitivos, de origens utilitárias e informativas (OliveiraCastro, 2003). No conceito de reforços utilitários as consequências no consumo e uso do produto resultam em utilidade para o consumidor, beneficiando-o na resolução de problemas e outras tarefas. Desta maneira os reforços utilitários são atribuídos a propriedades do produto ou serviço adquirido, seus atributos funcionais. Apesar de estar ligado ao valor do uso, o reforço utilitário deriva não apenas do desempenho funcional do produto, mas também dos sentimentos associados a eles, corresponde a uma satisfação direta que os bens e serviços promovem aos seus usuários, podendo estar associados com respostas prazerosas para o consumidor (Rosenthal, 2009).

As punições utilitárias possuem conceito inverso aos reforçadores, em que a utilidade do produto não está proporcionando resoluções ou resultando satisfação ao consumidor. Reforços informativos podem ser também denominados "simbólicos", pois resultam do status social obtido pelo consumidor no consumo do produto ou serviço, desta maneira os reforços informativos referem-se a consequências que igualmente sinalizam a probabilidade de uma ocorrência futura das respostas, mas pela aceitação e reconhecimento de outros. Também de natureza social, as punições informativas são interpostas por meio do comportamento de outros indivíduos, em que o consumidor se sente depreciado socialmente em consequência do produto ou serviço consumido, possuindo efeito inverso ao dos reforços informativos, desta maneira proporciona diminuição da probabilidade futura de ocorrência das respostas de consumo (Nalini, Melo Cardoso, \& Cunha, 2013). É importante ressaltar que um produto pode ao mesmo tempo apresentar reforços utilitários e informativos (Pohl \& OliveiraCastro, 2008).

Por conseguinte, Foxall (1997) aponta que as marcas dentro de uma determinada categoria de produtos sinalizam utilidade e simbolizo, referindo-se aos reforços utilitário e informativo, respectivamente. Essas marcas são tratadas como substituíveis porque suas demonstrações funcionais são (quase) idênticas. Estudos de Foxall, Oliveira-Castro e Schrezenmaier (2004), usando dados de painel de consumidores no Reino Unido, demonstraram que os consumidores realizam suas compras em torno de $70 \%$ em apenas um nível de diferenciação de marcas, alguns consumidores maximizam reforços informativos comprando somente marcas premium, outros maximizam reforços utilitários comprando apenas marcas com menor preço. Existe ainda outro grupo de compradores que se encontram entre esses dois tipos, realizando compras multimarcas, procurando tanto maximizar reforços utilitários quanto informativos (Oliveira-Castro, Cavalcanti, \& Foxall, 2016).

\section{METODOLOGIA: MÉTODOS E TÉCNICA}

A partir da proposta interpretativa do $B P M$ e as possíveis contribuições para a compreensão dos efeitos funcionais e simbólicos de produtos sobre o comportamento do consumidor, esta pesquisa, de caráter experimental tem como objetivo comparar a avaliação dos participantes em relação às marcas próprias e marcas de fabricante nos testes às cegas e testes de marcas reveladas, tendo como abordagem teórica o BPM. Portanto, o estudo analisa no processo de decisão de consumo, a influência dos reforços utilitários da variável dependente no teste às cegas e no teste de marcas reveladas, a influência os reforços informativos e utilitários; para registrar a diferença de avaliação verbal dos participantes na degustação dos produtos de marca própria em relação aos produtos de marca do fabricante. Para tanto, os participantes da pesquisa degustaram cookies de uma marca de fabricantes (Bauducco) e de três marcas próprias (Carrefour, Great Value e Qualitá). Um grupo saboreou o produto sem saber o nome da marca, enquanto os participantes do outro grupo visualizaram o nome das respectivas marcas.

Pretende-se com esse estudo poder avançar no conhecimento sobre a influência dos conceitos do Behavioral Perspective Model (BPM) para analisar e comparar os efeitos dos reforços informativos e utilitários das marcas de fabricantes e marcas próprias nos testes às cegas e testes de marcas reveladas. 


\section{Participantes}

O Estudo contou com um experimento intergrupos, sendo um grupo com 20 participantes para o teste às cegas e o outro grupo, também com 20 participantes para o teste de marcas reveladas. Há média de idade de 35,90 anos para os dois grupos, sendo de 38,80 anos para o grupo do teste às cegas e de 33 anos para o grupo do teste de marcas. Em relação ao sexo, 65\% de todos os participantes foram do sexo feminino e $35 \%$ do sexo masculino. Os participantes foram selecionados a partir de uma amostra de conveniência, composta por alunos de três cursos de Pós-graduação Stricto Sensu de duas universidades de Goiás e foram distribuídos randomicamente entre os dois grupos.

\section{Cenário}

As coletas foram realizadas em duas universidades de Goiás, sendo na sala de observação de uma universidade e na sala de Orientação da outra universidade. Os experimentos foram realizados em ambiente com temperatura e iluminação controladas. As salas eram mobiliadas com uma mesa e duas cadeiras, uma para o experimentador e outra para o participante da pesquisa.

\section{Instrumentos, Materiais e Equipamentos}

Sobre a mesa foram expostos quatro recipientes plásticos com uma metade de cookie com indicação nas tampas pelas letras "W, X, Y e Z" para teste às cegas e para o teste de marcas reveladas os nomes das marcas Carrefour, Qualitá, Great Value e Bauducco, este selecionado conforme por ser uma marca e fabricante líder no mercado. Ainda sobre a mesa havia três recipientes plásticos com um pedaço de maçã a ser usado após cada degustação, um copo descartável e uma garrafa com água, da qual o experimentador oferecia $50 \mathrm{ml}$ após a degustação do pedaço de cookie de cada marca. Também havia o protocolo para registrar os resultados das degustações e o Termo de Consentimento Livre e Esclarecido (TCLE) para assinatura.

\section{Procedimento}

Houve três sessões de aplicação da tarefa experimental de testes às cegas e de teste de marcas reveladas com 17 participantes na primeira, 13 na segunda e 10 na última sessão. Cada participante foi levado à sala individualmente, na qual estavam disponíveis três pedaços de maçã de mais ou menos $2,5 \mathrm{~cm}^{2}$ e as quatro metades de cada marca de cookies para a degustação. Ao início, os três pedaços de maçãs estavam em três recipientes plásticos transparentes com tampa de cor rosa. As metades de cada marca de cookie estavam armazenadas em recipientes de plástico transparentes com tampas de cor roxa e identificados com suas respectivas marcas para o teste de marcas reveladas e com letras para o teste às cegas.

Para realizar a degustação dos cookies, em ambos os testes, ao início de cada experimento, foram apresentadas instruções detalhadas para os diferentes testes: Teste às cegas e Teste de marcas reveladas. Em seguida, o experimentador ofereceu a cada participante uma metade de cookie de uma das quatro marcas pesquisadas, sendo esse processo repetido para todas as marcas, mas uma de cada vez, de forma randômica para apresentação das marcas. Após a apresentação de cada pedaço, o participante provou o cookie e indicou no protocolo em escala Likert de 1 a 5 os níveis de qualidade, sabor e textura do produto degustado, sendo 5- excelente, 4- muito bom, 3- bom, 2-regular e 1- ruim. Entre cada prova de degustação dos cookies, o participante ingeriu $50 \mathrm{ml}$ de água e comeu o pedaço de maçã apresentado pelo experimentador. Dois minutos após esse processo de lavagem residual de sabor da boca, realizou-se a próxima degustação da outra metade de cookie até a degustação de todos os quatro pedaços, seguindo a mesma sistemática descrita acima.

Metade dos participantes foi exposto à degustação sem indicação da marca dos cookies provado, com indicação na tampa do recipiente plástico de cada marca pelas letras "W, X, Y e Z" para as respectivas marcas "Carrefour, Qualitá, Great Value e Bauducco". Para a outra metade, no momento da degustação dos cookies, também na tampa do recipiente plástico estava colado o rótulo da marca de cada pedaço de cookie a ser provado: respectivamente "Carrefour, Qualitá, Great Value e Bauducco". A ordem das marcas ou das posições das letras para prova e identificação das marcas nos protocolos foi randomizada, para evitar viés na coleta dos dados. 


\section{Análise de dados}

As avaliações pós degustação foram analisadas a partir de testes não paramétricos intra e inter grupos. Para comparar as avaliações dos níveis individuais em cada um dos grupos, as respostas dos participantes foram analisadas para cada par de marcas com o Teste Wilcoxon Signed Rank Test. Para as comparações entre os grupos de teste cego e de marcas reveladas utilizou-se para cada par de marcas o Mann Whitney $U$. Esses testes baseiam-se em comparações ordinais, atribuindo postos aos valores e não exigem uma distribuição normal (Siegel, \& Castelan, 2006). Em ambos os casos se utilizou como critério de significância $\mathrm{p} \leq 0,05$.

\section{RESULTADOS}

Os 40 participantes dos grupos, sejam eles do teste às cegas ou teste de marcas reveladas, ao degustar cada pedaço de cookie registaram em um protocolo suas avaliações em escala Likert (1932) de 5 a 1 , sendo 5 a melhor ponderação e a 1 a pior nota, em três diferentes características, a saber: qualidade, sabor e textura. 0 resultado dos dados sobre qualidade dos testes de marcas reveladas e de testes às cegas está representado na Figura 1.

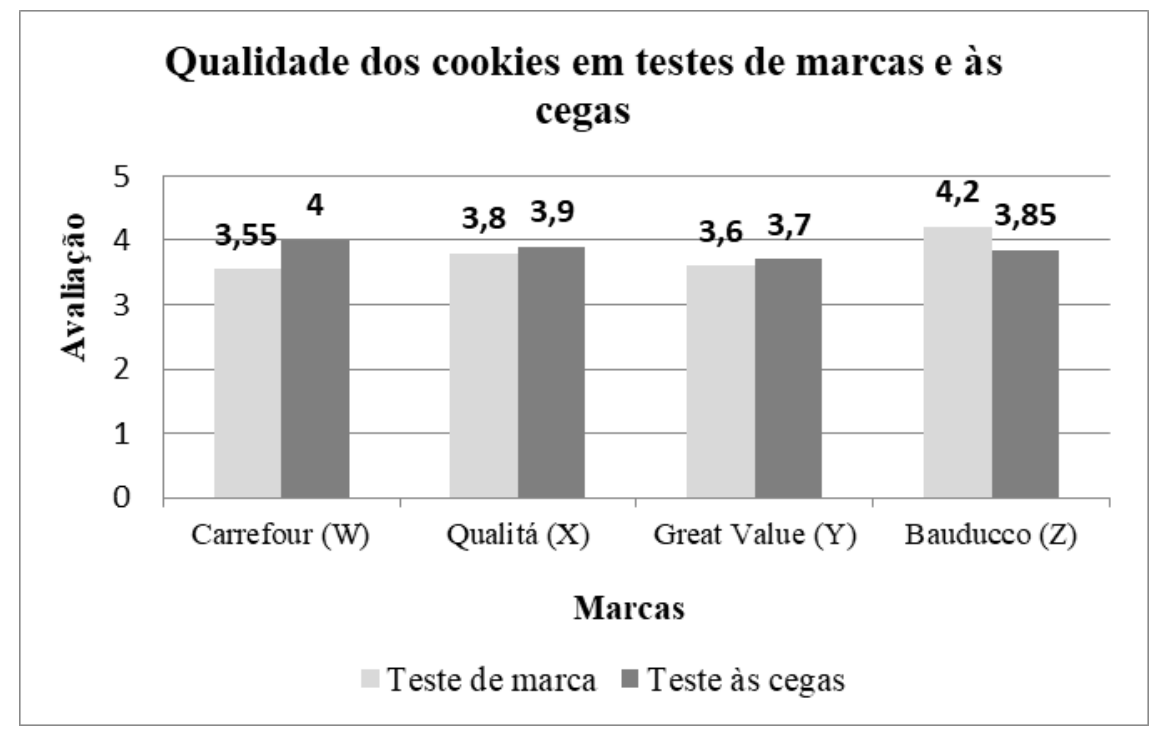

Figura 1 - Avaliações dos participantes para a característica qualidade nos testes de marcas e às cegas

As avaliações de qualidade no teste de marcas variaram de 3,55 (Carrefour) a 4,2 (Bauducco). No teste às cegas, a qualidade variou de 3,7 (Great Value) a 4,0 (Carrefour). Em relação às marcas próprias Carrefour, Qualitá e Great Value os dados apontam as seguintes informações: a marca W, Carrefour, no teste às cegas alcançou valores levemente mais altos de médias no quesito qualidade. As marcas próprias Qualitá e Great Value em qualidade alcançaram índices homogêneos de avaliação pelos participantes, tanto nos testes de marcas como nos testes às cegas, mas a marca Y, Great Value, foi avaliada com valores um pouco abaixo das outras marcas no teste às cegas. Ao analisar os dados do teste de marcas reveladas, o resultado mostra que a marca Bauducco apresentou a média de qualidade de mais alto valor.

0 resultado dos dados sobre sabor dos testes de marcas reveladas e de testes às cegas está representado na Figura 2, com a marca própria X, Qualitá, apontando pequeno melhor resultado no quesito sabor nos testes às cegas. 


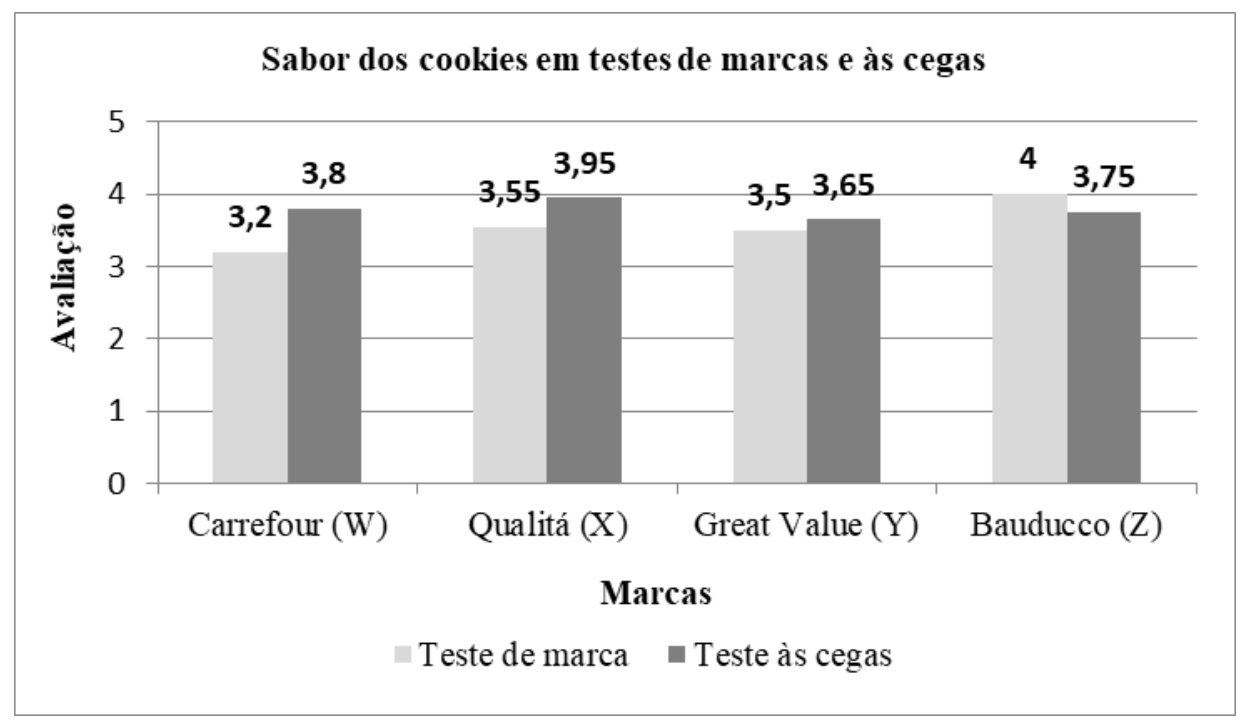

Figura 2 - Avaliações dos participantes para a característica, sabor nos testes de marcas e às cegas.

Os dados apontam que a marca própria Carrefour no quesito sabor no teste de marca alcançou valor mais baixo que as outras marcas. A marca própria Great Value, como em qualidade, no quesito sabor alcançou índices semelhantes de avaliação em ambos os testes de marcas e as cegas. A marca de fabricante Bauducco, também no quesito sabor alcançou o mais elevado índice no teste de marcas reveladas, contudo, sua avaliação no teste às cegas foi inferior à obtida pelas marcas Carrefour e Qualitá.

No quesito textura, no teste às cegas, as marcas Carrefour e Bauducco receberam as mesmas notas e foram as mais elevadas do que as duas outras marcas próprias X, Qualitá, e Y, Great Value, conforme Figura 3.

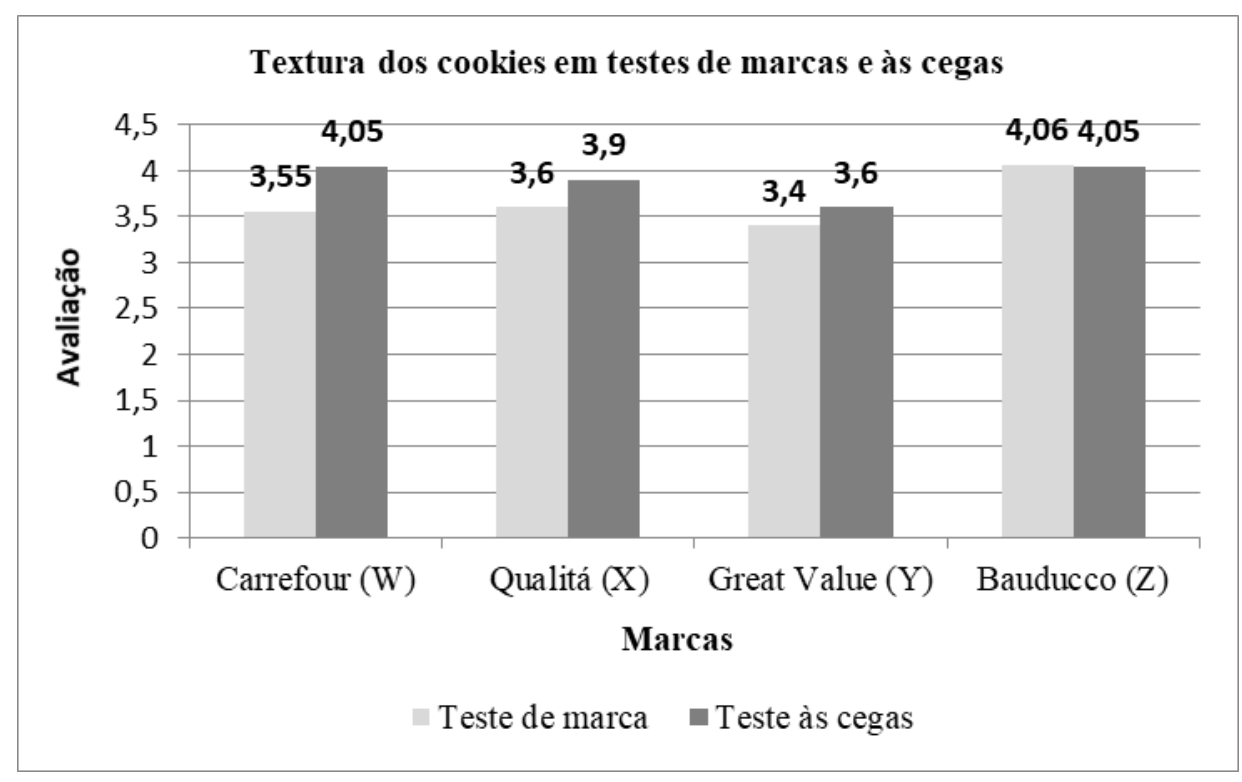

Figura 3 - Avaliações dos participantes para a característica, textura nos testes de marcas e às cegas.

A marca Great Value no quesito textura obteve as mais baixas notas tanto no teste de marcas quanto no teste às cegas. Já a marca de fabricante Bauducco, no quesito textura novamente alcançou, com pequena diferença, o mais alto valor no teste de marcas reveladas. Resumindo, a marca de fabricante Bauducco obteve, nesse modo, os valores mais altos nas três características qualidade, 
sabor e textura do que as outras três marcas próprias nos testes de marcas reveladas. Mas nos testes às cegas as marcas próprias Carrefour, Qualitá, e Great Value, e marca de fabricante Bauducco, obtiveram valores muito semelhantes. 0 que mostra que a níveis de reforços utilitários as marcas próprias e marcas de fabricante, por possuírem processo de fabricação semelhante ao da marca de fabricante, conforme pesquisa sobre fornecedores de marcas próprias de Rezende (2013) apresentam características funcionais muito semelhantes.

Ao agrupar as três médias das características; qualidade, sabor e textura em uma única média para cada uma das três marcas próprias (Carrefour, Qualitá e Great Value) e a marca de fabricante Bauducco verificou-se que as marcas próprias Carrefour e Qualitá alcançaram os maiores valores em médias nos testes às cegas. Enquanto no teste de marcas, todas as marcas próprias tiveram como resultado os menores índices ficando no máximo em torno de $(3,65)$ para a marca Qualitá. Desse modo, no teste de marcas reveladas a marca de fabricante Bauducco com $(4,06)$ foi a mais escolhida pelos participantes, Figura 4.

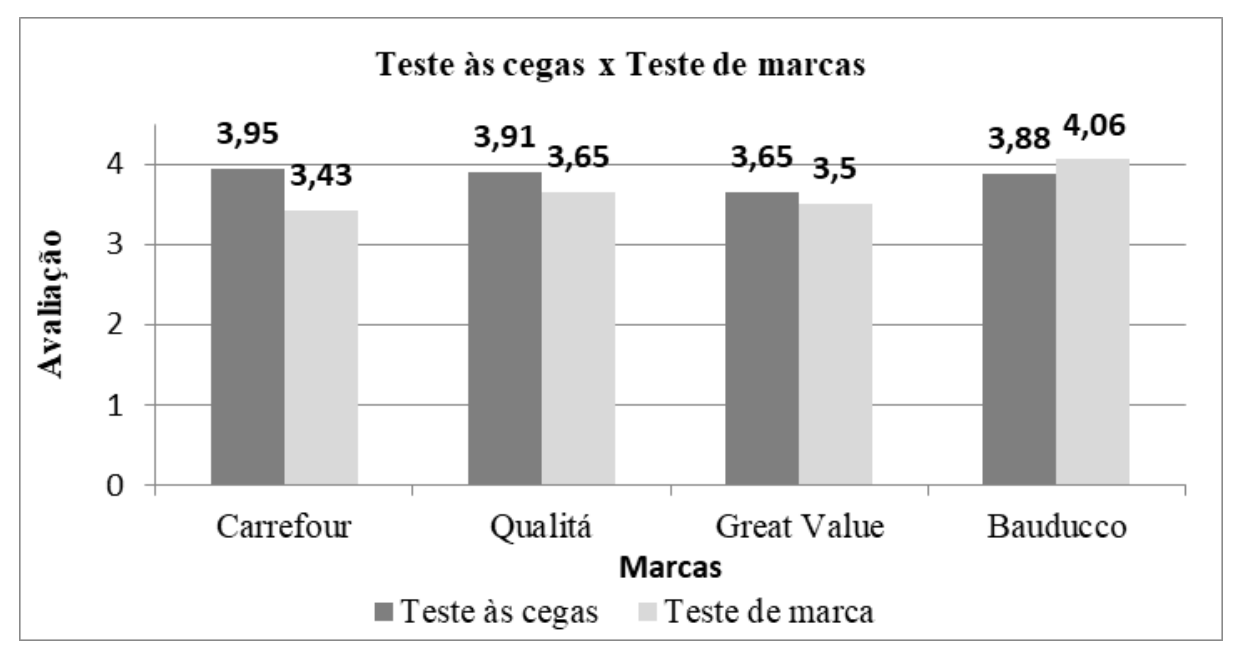

Figura 4 - Escores da união das médias de qualidade, sabor e texturas das marcas pesquisadas dos testes de marcas $x$ testes às cegas.

O resultado da Figura 4 está em consonância com a pesquisa de Oliveira-Castro, Foxall, James, Pohl, Dias e Chang (2008) ao informar que as marcas com baixo nível informativo diminui a probabilidade de aumento de frequência de compra, fato este destacado pelos baixos índices nos resultados das marcas próprias nos resultados dos testes de marcas reveladas.

Após aplicação do "Wilcoxon Signed Rank Test" para verificar a existência de diferença estatística significativa entre as médias das marcas representadas por letras $\mathrm{W}, \mathrm{X}, \mathrm{Y}$ e Z, respectivamente Carrefour, Qualitá, Great Value e Bauducco, entre si nos testes às cegas nas características qualidade, sabor e textura observou-se que nenhuma diferença entre as características pesquisadas foi significativa (Tabela 1).

\section{Tabela 1}

Valor de p obtidos a partir do teste Wilcoxon Pairs Signed Rank Test na comparação das amostras relacionadas de qualidade, sabor e textura das três marcas próprias e uma marca de fabricante de cookies dos testes às cegas.

\begin{tabular}{ccccccccccccc}
\hline & \multicolumn{1}{c}{ Teste às cegas / } \\
QUALIDADE & \multicolumn{1}{c}{ Teste às cegas / SABOR } & \multicolumn{3}{c}{ Teste às cegas /TEXTURA } \\
\hline & $\mathbf{W}$ & $\mathbf{X}$ & $\mathbf{Y}$ & $\mathbf{Z}$ & $\mathbf{W}$ & $\mathbf{X}$ & $\mathbf{Y}$ & $\mathbf{Z}$ & $\mathbf{W}$ & $\mathbf{X}$ & $\mathbf{Y}$ & $\mathbf{Z}$ \\
\hline $\begin{array}{c}\mathbf{W} \\
\text { Carrefour }\end{array}$ & .642 & .211 & .651 & & .584 & .520 & .971 & & .471 & .190 & .892 \\
$\begin{array}{c}\mathbf{X} \\
\text { Qualitá }\end{array}$ & & & .251 & .971 & & & .299 & .607 & & & .162 & .588 \\
\end{tabular}




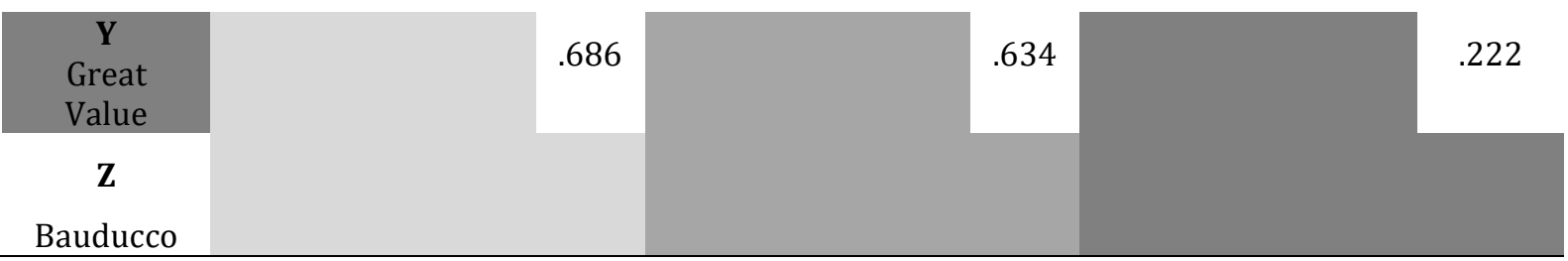

Asymptotic significances are displayed. The significance level is ,05

Ao aplicar o "Wilcoxon Signed Rank Test" com o mesmo propósito de verificar a existência de diferença estatística significativa entre as médias das marcas, nos testes de marcas reveladas, em que elas eram representadas pelos seus respectivos nomes: Carrefour, Qualitá, Great Value e Bauducco, observou-se três diferenças significativas (Tabela 2).

\section{Tabela 13}

Valor de p obtidos a partir do teste Wilcoxon Pairs Signed Rank Test na comparação das amostras relacionadas de qualidade, sabor e textura das três marcas próprias e uma marca de fabricante de cookies dos testes de marcas.

\begin{tabular}{|c|c|c|c|c|c|c|c|c|c|c|c|}
\hline \multicolumn{4}{|c|}{ Teste de marcas / QUALIDADE } & \multicolumn{4}{|c|}{ Teste de marcas / SABOR } & \multicolumn{4}{|c|}{ Teste de marcas / TEXTURA } \\
\hline & $\begin{array}{l}\text { Quali } \\
\text { tá }\end{array}$ & $\begin{array}{l}\text { Great } \\
\text { Value }\end{array}$ & $\begin{array}{c}\text { Baudu } \\
\text { cco }\end{array}$ & $\begin{array}{c}\text { Carref } \\
\text { our }\end{array}$ & $\begin{array}{l}\text { Quali } \\
\text { tá }\end{array}$ & $\begin{array}{l}\text { Great } \\
\text { Value }\end{array}$ & $\begin{array}{c}\text { Baudu } \\
\text { cco }\end{array}$ & $\begin{array}{c}\text { Carref } \\
\text { our }\end{array}$ & $\begin{array}{l}\text { Quali } \\
\text { tá }\end{array}$ & $\begin{array}{l}\text { Great } \\
\text { Value }\end{array}$ & $\begin{array}{c}\text { Baudu } \\
\text { cco }\end{array}$ \\
\hline Carrefour & .524 & .796 & .050 & & .321 & .211 & .050 & & .847 & .577 & .235 \\
\hline Qualitá & & .352 & .163 & & & .897 & .146 & & & .372 & .339 \\
\hline $\begin{array}{l}\text { Great } \\
\text { Value }\end{array}$ & & & .040 & & & & .135 & & & & .072 \\
\hline Bauducco & & & & & & & & & & & \\
\hline
\end{tabular}

Asymptotic significances are displayed. The significance level is ,05

Desse modo, ao comparar a marca Carrefour com a marca Bauducco no quesito qualidade, observou o resultado de $\mathrm{p}=0,050$, o que indica que houve diferença entre esta característica nas marcas. A média da marca Carrefour em qualidade foi de 3,55 enquanto a média da marca Bauducco também para qualidade foi de 4,2. Na comparação da marca Bauducco com a marca Great Value no quesito qualidade, observou o resultado de 0,040, indicando também a existência de diferenças significativas entre elas, com Bauducco apresentando maior avaliação.

No quesito sabor a comparação das marcas Carrefour e Bauducco apresentou diferença estatística significativa de 0,05. A média da marca Carrefour para sabor foi de 3,2, enquanto a média da marca Bauducco para este quesito foi 4.

A obtenção de avaliações iguais ou mais altas para as marcas próprias no grupo do teste às cegas e maiores para a marca de fabricante no teste de marcas reveladas apresentaram sistematicidade. Para avaliar o poder estatístico das diferenças das avaliações de cada cookie com e sem marca foi aplicado o teste Mann Whitney $U$, separadamente para cada atributo. As comparações das avaliações nos testes às cegas indicaram semelhanças entre todas as comparações. Para o cookie Carrefour os valores foram: Qualidade ( $W=359, p=0,149)$, Sabor $(W=349,5, p=0,091)$ e Textura (W $=351.1, \mathrm{p}=0,100)$. Para o cookie Qualitá as comparações geraram: Qualidade $(\mathrm{W}=403, \mathrm{p}=0,832)$, Sabor (W = 367,5, p = 0,238) e Textura (W = 382,5, $\mathrm{p}=0,445)$. Para o cookie Great Value: Qualidade $(\mathrm{W}=400,5, \mathrm{p}=0,800)$, Sabor $(\mathrm{W}=395, \mathrm{p}=0,685)$ e Textura $(\mathrm{W}=389, \mathrm{p}=0,568)$. Para a marca própria, Bauducco: Qualidade ( $\mathrm{W}=459, \mathrm{p}=0,164)$, Sabor $(\mathrm{W}=444,5, \mathrm{p}=0,335)$ e Textura $(\mathrm{W}=415, \mathrm{p}$ $=0,897)$.

No geral, as avaliações das marcas próprias tenderam a ser sistematicamente mais baixas que as avaliações da marca de fabricante nos testes de marcas reveladas, contudo, apenas três avaliações: 
qualidade e sabor entre Bauducco e Carrefour; e qualidade entre Bauducco e Great Value foram significativas.

\section{DISCUSSÃO}

Esta pesquisa objetivou a aplicação do modelo teórico Behavioral Perspective Model (BPM) para analisar como consumidores avaliam produtos de marcas próprias em relação a produtos de marcas de fabricante. Partiu-se do entendimento de que, como a concorrência aumentou e diferentes empresas e marcas estão disponíveis no mercado, diferenciar-se por meio de suas marcas tornou-se estratégia para alcançar vantagens competitivas sobre os concorrentes. As redes supermercadistas que têm grande representatividade para a economia brasileira, ao manter índices de crescimento consideráveis como incrementos nas vendas, visualizaram no comércio das marcas próprias uma importante tática para o negócio de varejo. Com essa estratégia, puderam viabilizar o aumento da competitividade do varejista, e isso impacta na melhoria de sua rentabilidade e lucratividade.

A partir do referencial teórico acerca do tema, evidenciou-se a necessidade da compreensão do comportamento dos consumidores em suas peculiaridades e as várias descobertas a respeito do comportamento do consumidor no processo de escolha de marcas, chave para o sucesso das estratégias de marketing das empresas. 0 resultado da pesquisa sobre esse questionamento foi alcançado, pois se analisou a influência dos reforços informativos e utilitários no comportamento do consumidor de cookies de marcas próprias versus marcas de fabricantes com aplicação do modelo teórico Behavioral Perspective Model (BPM).

0 resultado do teste de marcas reveladas mostra que a marca Bauducco apresentou as médias de qualidade, sabor e textura com os mais altos valores, demostrando influência da marca como sinalizadora de níveis de reforços informativos e utilitários. As três marcas próprias Carrefour, Qualitá e Great Value mostraram no teste de marcas reveladas um padrão mais baixo de avaliação. Entretanto, a conclusão básica ao teste às cegas não indicou diferenças significativas entre a marca de fabricante e marcas próprias. Assim as marcas poderiam ser facilmente substituídas pelas outras. Os resultados apontaram que as três marcas próprias (Carrefour, Qualitá e Great Value) mostraram valores levemente mais altos no teste as cegas do que no teste de marcas reveladas e semelhantes aos da marca Bauducco. 0 resultado do teste "Wilcoxon Signed Rank Test" mostrou que não houve nenhuma diferença estatística significativa entre as médias das marcas Carrefour, Qualitá, Great Value e Bauducco para as características pesquisadas, qualidade, sabor e textura quando foram identificadas.

Os resultados evidenciam um baixo controle discriminativo de estímulos relacionados às marcas próprias, inferindo baixo índice de reforços informativos e indicando à ineficácia das estratégias de marketing utilizadas para expansão desse modelo de patrocínio de marcas voltadas à oferta de produtos como de vantagem competitiva no mercado como nas pesquisas de Oliveira-Castro et al. (2008) e, mais recente de Pedroso (2016). Labeage, Lago e Matos (2007) e De Wulf e colaboradores (2005), ainda que em pesquisas com base teórica diferente desta, afirmaram que a lealdade comportamental da marca própria está na base do patrimônio da marca porque a participação em testar uma marca é maior em categorias com baixo risco percebido pelo consumidor, podendo assim inferir que lealdade à marca está associada ao índice informativo da empresa que gerencia a marca própria.

Ao verificar a existência de diferença estatística significativa entre si, das médias das marcas Carrefour, Qualitá, Great Value e Bauducco no teste de marcas reveladas, os dados indicam controles discriminativos presentes no cenário de compra que ao mesmo tempo podem aumentar o valor reforçador das marcas de fabricante e reduzir o valor reforçador das marcas próprias. Esses dados apontam para a possibilidade de que baixos níveis de conhecimento e qualidade associados a baixa frequência de consumo podem dificultar o controle por propriedades funcionais/utilitárias das marcas próprias.

Deve ser considerado que o comportamento do consumidor pode estar sob o controle de reforços informativos ou de utilitários em diferentes níveis (Foxall, 1998). Nesta pesquisa, esses reforços foram analisados separadamente. Os reforços utilitários foram considerados nos testes às cegas e os reforços utilitários e informativos nos testes de marcas reveladas. 
Nos testes de marcas reveladas, os reforços informativos e utilitários foram relevantes no processo de escolha dos produtos de marcas de fabricantes, o que corrobora com Pohjanheimo e Sandell (2009) que comentaram que as informações do produto como nome do fabricante, a marca, o sabor e a imagem do pacote comercial tiveram efeitos positivos e significativos nas pontuações hedônicas das médias dos iogurtes finlandeses e um pequeno efeito positivo nas pontuações sobre a preferência de gosto do iogurte checo. Labeage, Lago e Matos (2007) sugerem para maior envolvimento da marca própria com os consumidores, deve-se usar a estratégia de distribuição de amostras grátis, estabelecendo estímulos discriminativos de espaço (cenário) e tempo (histórico de aprendizagem) na probabilidade de reforços futuros.

Neste contexto, os dados são concordantes com o de De Wulf e colaboradores (2005) que afirmam que marcas fortes integram os benefícios funcionais e emocionais relevantes para o consumidor, construindo atributos concretos e abstratos que são suficientemente conhecidos e são percebidos como diferentes da concorrência. A partir do referencial do BPM, Yan, Foxall e Doyle (2012) ressaltaram que o reforço informativo varia consideravelmente de consumidor para consumidor, dependendo das histórias e valores de aprendizagem dos consumidores..

As informações fundamentais do estudo de Vraneševicv e Stančec (2003) são que os consumidores não valorizam produtos baseados exclusivamente em suas características físicas. No processo de tomada de decisão de compra, ao escolher uma alternativa, os consumidores, já de início, percebem a marca como "um sinal de qualidade" e depois outros critérios de avaliação (aparência física e embalagem, preço, reputação da rede de varejo). As considerações de Silva (2007) completam essa ideia e considera que o consumidor no processo de escolha de um produto, uma marca é comparada em detrimento de outra o que corrobora com Vraneševicv e Stančec (2003) ao afirmar que uma marca de produto considerada premium, de boa qualidade, pode dar valor adicional ao produto, isto é, a marca de um produto tem um valor de mercado que representa algo adicional como, por exemplo, uma marca pode representar um status positivo para o consumidor.

Ejye Omar (1994) mostrou em seu experimento, como as marcas próprias foram posicionadas psicologicamente abaixo das marcas de fabricante em muitos níveis de escalas. 0 mesmo foi identificado nesta pesquisa porque as marcas próprias foram identificadas e/ou vistas como inferiores à da marca de fabricante no teste de marcas reveladas. Mas as marcas próprias foram relatadas como sendo particularmente quase idênticas à marca de fabricante no teste às cegas, salientando os efeitos dos reforços utilitários. Desse modo, como na pesquisa de Ejye Omar (1994) testados por apenas alguns dos consumidores, em dimensões do comportamento, distinguiram marcas de fabricante e marcas próprias em altos níveis de escalas e com percentuais racionalmente significativos nas diferenças de prova e experimentação sobre os dois tipos de marcas.

No relato de Oliveira-Castro, Cavalcanti e Foxall (2016) o nível de reforço informativo das marcas mostrou efeitos significativos, mas pequenos, sobre a quantidade de gasto, quando relacionados a produtos alimentares rotineiros. Neste estudo, as marcas próprias foram identificadas e/ou vistas como inferiores às das marcas de fabricante, quando avaliadas em relação aos reforços informativos e utilitários em alguns quesitos. Mas no teste de marcas reveladas, as marcas próprias foram relatadas como sendo, particularmente semelhantes, às marcas de fabricantes, o que contradiz com Ejye Omar (1994) ao descrever em seu experimento de marcas reveladas que as marcas próprias foram posicionadas psicologicamente abaixo das marcas de fabricante em muitos níveis de escalas.

\section{CONCLUSÕES E RECOMENDAÇÕES}

Por fim, a partir deste trabalho conclui-se que as avaliações nos testes às cegas e nos testes de marcas de cookies de uma marca de fabricante e de três marcas próprias diferenciaram-se. Com a apresentação das marcas, as avaliações das marcas próprias foram mais baixas que a da marca de fabricante, ao passo que no teste às cegas as quatro marcas tiveram avaliações próximas e as marcas de fabricante foram avaliadas mais positivamente nessa condição em comparação com o teste de marcas. Esses dados sugerem o efeito da apresentação da marca de sinalizar alto nível de reforço informativo para a marca de fabricante e baixo nível de reforço informativo para as marcas próprias, a despeito das semelhanças funcionais observadas nos testes às cegas. Neste caso, e a partir das análises 
realizadas, é possível supor que as diferenças e semelhanças encontradas podem refletir as avaliações dos participantes em um contexto controlado, tal como foi planejado no presente experimento.

A viabilidade de interpretação suportada pelo BPM tem se mostrado uma ferramenta importante na compreensão do comportamento do consumidor e pode contribuir para estratégias de marketing e gerenciais, mas principalmente para auxiliar os consumidores a identificarem os controles sobre seu comportamento e realizarem escolhas que são mais benéficas para si. No presente caso, produtos funcionalmente semelhantes podem indicar um consumo mais focado nas propriedades dos produtos que nos aspectos simbólicos das marcas, com mais acesso e menos custo para o consumidor. Apesar disso, como as marcas próprias são fabricadas por empresas diferentes, não se pode considerar que as semelhanças aqui encontradas se aplicam a outras marcas.

Dessa forma, ressalta-se que a presente pesquisa apresenta algumas limitações que precisam ser consideradas. Com relação às características da amostra, a população da qual foi retirada (alunos de pós-graduação de duas universidades), o tamanho da amostra e ausência de um balanceamento entre participantes dos diferentes sexos reduz a possibilidade de extrapolação para populações maiores. Com relação aos produtos e marcas, as avaliações foram realizadas com quatro marcas de um produto, dos quais apenas um de marca de fabricante, o que também limita fazer inferências sobre o comportamento de compra na presença de outras marcas na prateleira de um supermercado.

Sugere-se para estudos futuros a ampliação para diferentes produtos das investigações que possibilitam comparar as influências de níveis de reforço informativo e utilitário de marcas próprias e marcas de fabricante. Adicionalmente, a realização de outras pesquisas com amostras randomizadas também possibilitarão maior nível de inferência para populações mais amplas.

\section{References}

Aaker, D. A. (1998). Brand equity: gerenciando o valor da marca. 2. ed. São Paulo: Negócio Editora, 1998.

Aaker, D. A. (2001). Criando e administrando marcas de sucesso. 3. ed. São Paulo: Futura.

Aaker, D. A. (2007). Estratégia de portfólio de marcas. Porto Alegre: Bookman.

American Marketing Association. Dictionary. Recuperado em 05 de julho, 2019 de https://www.ama.org/resources/Pages/Dictionary.aspx?dLetter=P.

Amrouche, N., \& Yan, R. (2012). Implementing online store for national brand competing against private label. Journal of Business Research, 65(3), 325-332.

Chen, J., Narasimhan, O., John, G., \& Dhar, T. (2010). An empirical investigation of private label supply by national label producers. Marketing Science, 29(4), 738-755

De Chernatony, L. (2005). Construção de marca. In: BAKER, M. J. et al. Administração de Marketing. 5. ed. Rio de Janeiro: Campus (Elsevier), cap. 15.

De Chernatony, L., \& Dall'olmo Riley, F. (1998). Defining a brand: beyond the literature with experts' interpretations, Journal of Market. Management, 14, 417-443.

De Wulf, K., Odekerken-Schröder, G., Goedertier, F., \& Van Ossel, G. (2005). Consumer perceptions of store brands versus national brands. Journal of Consumer marketing, 22(4), 223-232.

Ejye Omar, O. (1994). Comparative product testing for own-label marketing. International Journal of Retail \& Distribution Management, 22(2), 12-17.

Foxall, G. R. (1987). Radical behaviorism and consumer research theoretical promise and empirical problems. International Journal of Research in Marketing, 4(2)

Foxall, G. R. (1990). Consumer Psychology in Behavioral Perspective. London e New York: Routledge.

Foxall, G. R. (1992). The Behavioral Perspective Model of purchase and consumption: From consumer theory to marketing practice. v.20, n.2, pp.189-198. Journal of the academy of marketing science.

Foxall, G. R. (1997). Marketing Psychology: The paradigm in the wings. London: MacMillan.

Foxall. (1998). Radical Behaviorist Interpretation: Generating and evaluating an account of consumer behavior. The Behavior Analyst, 21, 321-354.

Foxall, G. R. (2005). Understanding Consumer Choice. New York: Palgrave McMillan. 
Foxall, G. R., Oliveira-Castro, J. M., \& Schrezenmaier, T. C. (2004). The behavioral economics of consumer brand choice: patterns of reinforcement and utility maximization. Behavioural Processes, 66, 235-260.

Hyman, M. R., Kopf, D. A., \& Lee, D. (2010). Review of literature-Future research suggestions: Private label brands: Benefits, success factors and future research. Journal of Brand Management, 17(5), 368-389.

Hoyer, W. D., \& Brown, S. P. (1990). Effects of brand awareness on choice for a common, repeatpurchase product. Journal of consumer research, 17(2), 141-148.

Keller, K. L., \& Machado, M. (2006). Gestão estratégica de marcas. São Paulo: Pearson Prentice Hall.

Kotler, P. (2000). Marketing para o século XXI: como criar, conquistar e dominar mercados. Futura.

Kumar, N., \& Steenkamp, J. B. E. (2008). Estratégia de marcas próprias: como enfrentar o desafio da marca de loja. M. Books.

Labeaga, J. M., Lado, N., \& Martos, M. (2007). Behavioural loyalty towards store brands. Journal of Retailing and consumer services, 14(5), 347-356.

Likert, R. (1932). A technique for the measurement of attitudes. Archives of Psychology, 140, 1-55.

Miquel-Romero, M. J., Caplliure-Giner, E. M., \& Adame-Sánchez, C. (2014). Relationship marketing management: Its importance in private label extension. Journal of Business Research, 67(5), 667672.

Nalini, L. E. E. G., Melo Cardoso, M. de, \& Cunha, S. R. (2013). Comportamento do Consumidor: uma introdução ao Behavioral Perspective Model (BPM). Fragmentos de Cultura, Goiânia, 23(4), 489505 , out./dez.

Nielsen (2017). 19ำ Estudo Anual de Marcas Próprias. The Nielsen Company. Confidential and proprietary.

Paula, V. A. F. (2008). Estratégia de marcas no varejo de alimentos: concepção e gestão de marcas próprias na Inglaterra e no Brasil. Tese (Doutorado em Engenharia de Produção) - Universidade Federal de São Carlos, São Carlos.

Pedroso, R. (2016). Valor Subjetivo do Consumo Sustentável. Tese de Doutorado. Universidade Católica de Goiás. Goiânia, GO.

Private Label Manufacturers Association (2017). Industry News. Private label today. Retirado em 06 de julho, 2017 de http://www.plmainternational.com/industry-news/private-label-today

Oliveira, R. N. A. (2005). Gestão Estratégica de Marca própria. Rio de Janeiro: Brasport, 2ª Ed. 2005. $256 \mathrm{p}$.

Oliveira-Castro, Jorge M. (2003). Effects of base price upon search behavior of consumers in a supermarket: an operant analysis. Journal of Economic Psychology, 24(5), 637-652.

Oliveira-Castro, J. M., Cavalcanti, P. R., \& Foxall, G. R. (2016). What consumers maximize: Brand choice as a function of utilitarian and informational reinforcement. Managerial and Decision Economics, 37(4-5), 360-371.

Oliveira-Castro, J. M. \& Foxall, G. R. (2005). Análise do Comportamento do Consumidor. Em J. A. Rodrigues \& M. R. Ribeiro (Orgs.). Análise do Comportamento: Pesquisa, Teoria e Aplicação. Porto Alegre: Artmed.

Oliveira-Castro, J. M., Foxall, G. R., James, V. K., Pohl, R. H., Dias, M. B., \& Chang, S. W. (2008). Consumerbased brand equity and brand performance. The Service Industries Journal, 28(4), 445-461.

Oliveira-Castro, J. M., Foxall, G. R., \& Wells, V. K. (2010). Consumer brand choice: Money allocation as a function of brand reinforcing attributes. Journal of Organizational Behavior Management, 30(2), 161-175.

Olson, E. L. (2012). Supplier inferences to enhance private label perceptions. Journal of Business Research, 65(1), 100-105.

Piato, E. L. (2011). Análise do alinhamento da estratégia de marcas próprias do atacado distribuidor em relação às perspectivas dos clientes varejistas. Tese - (Doutorado em Engenharia de Produção) Universidade Federal de São Carlos - UFSCar

Pohl, R. H., \& Oliveira-Castro, J. M. (2008). Efeitos do nível de benefício informativo das marcas sobre a duração do comportamento de procura. RAC-Eletrônica, 2(3), 499-469. 
Pohjanheimo, T., \& Sandell, M. (2009). Explaining the liking for drinking yoghurt: The role of sensory quality, food choice motives, health concern and product information. International Dairy Journal, 19(8), 459-466.

Rajala, A. K., \& Hantula, D. A. (2000). Towards a behavioral ecology of consumption: delay-reduction effects on foraging in a simulated Internet mall. Managerial and Decision Economics, 21(3-4), 145-158.

Rezende, S. R. G. (2013). Análise das estratégias de marcas em fornecedores de marcas próprias: estudo multicasos em fabricantes de produtos lácteos. Uberlândia, 2013. 182 f. Dissertação- (Mestrado em Administração) - Universidade Federal de Uberlândia - UFU

Rosenthal, B. (2009) Comportamento de consumo: uma análise dos fatores que controlam a escolha de bebidas. Seminários em Administração- SEMEAD, São Paulo. Anais eletrônicos.

Serralvo, F.A., Prado, K.P.L., \& Leal, C. A. (2007). A importância de marcas no contexto competitivo- 0 caso das Havaianas. XXX encontro de Marketing da ANPAD, 23.

Silva, M. S. V. (2007). Análise do Comportamento do consumidor: valor de equivalência e avaliação de qualidade e conhecimento de marcas de café. Dissertação (Mestrado em Psicologia) - Pontifícia Universidade Católica de Goiás, Goiânia.

Skinner, B. F. (1953/2000). Ciência e comportamento humano. 10aㅡ ed., Ed. Martins Fontes.

Skinner, B. F. (1957). Verbal behavior action. MA: Copley Publishing Group.

Skinner, B. F. (1974/ 2003). Sobre o behaviorismo. São Paulo. Cultrix.

Skinner, B. F. (1978). O comportamento verbal. São Paulo: Cultrix (Tradução de Maria da Penha Villalobos).

Souza, M. G. de, \& Nemer, A. (1993). Marca e distribuição: desenvolvendo dominação estratégica e vantagem competitiva no mercado global. Makron Books.

Tarziján, J. (2007). Should national brand manufacturers produce private labels? Journal of Modelling in Management, 2(1), 56-70.

Todorov, J. C. (2012). O conceito de contingência tríplice na Análise do Comportamento humano. Psicologia: Teoria e Pesquisa, 1(1), 75-88.

Urban, G. L., Hulland. J. S., \& Weinberg, B. D. (1993). Premarket forecasting for new consumer durable goods: Modeling categorization, elimination, and consideration phenomena. Journal of Marketing, 57, 2, 47- 62

Vraneševic, T., Stančec, R. (2003). The effect of the brand on perceived quality of food products. British Food Journal, 105(11), 811-825.

Yan, J., Foxall, G. R., \& Doyle, J. R. (2012). Patterns of reinforcement and the essential value of brands: II. evaluation of a model of consumer choice. The Psychological Record, 62(3), 377-394.

Yokoyama, M. H. (2010). Análise das estratégias de produção em fornecedores de marcas próprias: um estudo multicaso em empresas do setor de alimentos. Dissertação - (Mestrado em Engenharia de Produção) - Universidade Federal de São Carlos - UFSCar 